\title{
VULNERABILIDADE QUÍMICA DOS SOLOS A CONTAMINAÇÃO POR CHUMBO, EM ÁREA COM EXTRAÇÃO E CALCINAÇÃO DE CALCÁRIO NO ESTADO DE MINAS GERAIS - BRASIL.
}

\author{
Adriano F. de Moraes ${ }^{1}$; Adolf H. Horn².
}

\begin{abstract}
RESUMO
Entender a contaminação por chumbo demanda conhecer o seu comportamento e dos constituintes dos solos que interagem com ele. Foi estudada a Província Cárstica de Arcos-Pains-Doresópolis (MG). Mediram-se os teores de chumbo e a vulnerabilidade química do solo. As amostras foram analisadas na UFMG e UFV. Os resultados foram trabalhados em Microsoft Office Excel 2003 e ArcGis 9.2. Os teores de chumbo superaram os valores de prevenção $(72,0 \mathrm{mg} / \mathrm{kg})$. Numa amostra, o teor $(216,5 \mathrm{mg} / \mathrm{kg})$ ultrapassou os valores de intervenção agrícola $(180,0 \mathrm{mg} / \mathrm{kg})$. Nos solos hidromórficos a vulnerabilidade química é muito alta indicando restrições de usos que lancem chumbo.

Palavras-chave: calcários, solos e chumbo.
\end{abstract}

\begin{abstract}
Understanding the contamination by lead demand known its behavior and soil constituents that interact with it. It studied the Karstic Province of Arcos-Pains-Doresópolis (MG). It is quantified the levels of lead and vulnerability soil chemistry. The samples were analysed in UFMG and UFV. The results were worked out in Microsoft Office Excel 2003 and ArcGis 9.2. The levels of lead exceeded the values of prevention (72.0 $\mathrm{mg} / \mathrm{kg})$. In a sample the content $(216.5 \mathrm{mg} / \mathrm{kg}$ ) exceeded the values of agricultural intervention $(180.0 \mathrm{mg} /$ $\mathrm{kg}$ ). In the wet (hidromorfics) soil the vulnerability chemistry is very high indicating restrictions of uses to launch lead.

Keywords: limestones, soils and lead.
\end{abstract}

\section{INTRODUÇÃO}

A análise da contaminação dos solos por chumbo requer o conhecimento deste metal, dos constituintes dos solos que com ele interagem, assim como da intensidade destas interações. A partir daí, pode-se definir qual a real vulnerabilidade química do solo ao chumbo. Regiões de vulnerabilidade natural alta - como é o caso da região calcária onde se realizou este estudo - demandam atenção no seu uso.

A região estudada situa-se na província cárstica de Arcos-Pains-Doresópolis (MG), uma parte maior na porção meridional da bacia hidrográfica do Rio São Francisco e uma porção menor na bacia hidrográfica do Rio Grande. As amostras foram coletadas em áreas específicas dos municípios de Córrego Fundo, Pains e Arcos. Tal região destaca-se na produção de calcário e cal, outro setor de atividade importante é a agropecuária (Borghetti, 2002). A aptidão agrícola ocorre tendo em vista a fertilidade dos solos eutróficos. A região é constituída por rochas calcárias formadas principalmente pelos minerais carbonatos de cálcio (calcita e aragonita), carbonato de magnésio (magnesita) e carbonato de cálcio e magnésio (dolomita). Ressaltase que parte da área de estudo (porção localizada a sudeste) está sobre a fácie pelitos terrígenos. Todo esse sistema situa-se sobre embasamento gnáissicomigmatítico (Santos, 2002).

Considerando-se apenas a elevada condutividade da rocha calcária (Menegasse et al., 2002) e a presença dos metais pesados na sua forma catiônica seria coerente afirmar que o carste, como um todo (solos, rochas, águas, flora e fauna), estaria recebendo a carga poluidora dos empreendimentos dessas localidades. No entanto, os solos, por meio de seus muitos constituintes químicos, possuem uma grande capacidade de filtragem destes contaminantes graças às muitas interações físico-químicas com os cátions metálicos (Ianhez, 2003). As retenções ocorrem por vários mecanismos físico-químicos. As argilas retêm os metais por meio de adsorção eletrostática às suas superfícies carregadas negativamente. Os óxidos retêm tanto por adsorção (Paim, 2002) quanto pelo fenômeno da oclusão (Ianhez, 2003). A matéria orgânica funciona como uma espécie de quelante capaz de complexar os cátions metálicos mediante os ligantes oxigênio e nitrogênio presentes em sua estrutura e ricos em pares de elétrons. Segundo Matosinhos (2004), estas variáveis regem as interações solo-poluente-água.

Uma vez que a heterogeneidade do componente ambiental solo se deve aos fatores relacionados à constituição da rocha de origem e a fatores climáticos, a capacidade de retenção dos metais pesados por seus constituintes será diferente espacial e temporalmente. Desta forma, a vulnerabilidade química dos solos, bem como os riscos do chumbo ultrapassar este filtro natural também é uma função espacial e temporal (Karmann, 2001). Faz-se necessário, portanto, gerar modelos indicativos da mobilidade do chumbo nos solos para se calcular a vulnerabilidade química deste compartimento 
e inferir sobre os reais riscos ambientais presentes na área devido à presença de tal metal.

Neste contexto, os objetivos deste estudo foram definir espacialmente os teores de chumbo e dos constituintes dos solos capazes de retê-lo. Além disso, propor um modelo de cálculo da vulnerabilidade química dos solos a este metal com base nos teores destes constituintes, ponderados pelo teor de chumbo retido e pela força destas retenções. Por fim, inferir sobre os riscos ambientais da presença deste metal na área de estudo, assim como sobre as restrições de uso da mesma.

\section{PROCEDIMENTOS METODOLÓGICOS}

Foi escolhida uma área de $15 \mathrm{~km}^{2}(5 \mathrm{~km} \times 3 \mathrm{~km})$ heterogênea e que abrangesse as bacias hidrográficas do rio Grande e São Francisco, três grupos de solos (Argissolos, Latossolos e Gleissolos), dois aspectos geológicos (calcários dolomitos e pelitos terrígenos), diferentes usos (extração e beneficiamento de rochas calcárias, calcinação e agricultura) e áreas com vulnerabilidade natural reconhecidamente altíssimas (afloramento calcário e dolinas com sumidouros).

Foram coletadas, de acordo com Lemos \& Santos (1996), 39 amostras de solos nos primeiros $20 \mathrm{~cm}$ com o intuito de medir os teores de chumbo de origem antrópica e não aqueles provenientes da rocha de origem dos solos. A Figura 1 apresenta o mapa de localização da área.

A Figura 2 apresenta aspectos geomorfológicos da área de estudo com base nos quais as manchas e pontos de amostragem foram definidos. Também são indicados os empreendimentos localizados no local.

Das amostras obteve-se a terra fina seca ao ar TFSA (EMBRAPA, 1997) para análises posteriores. Em todas as amostras mediu-se o pH dos solos, em 20 delas mediu-se o teor total do chumbo e em 8 amostras
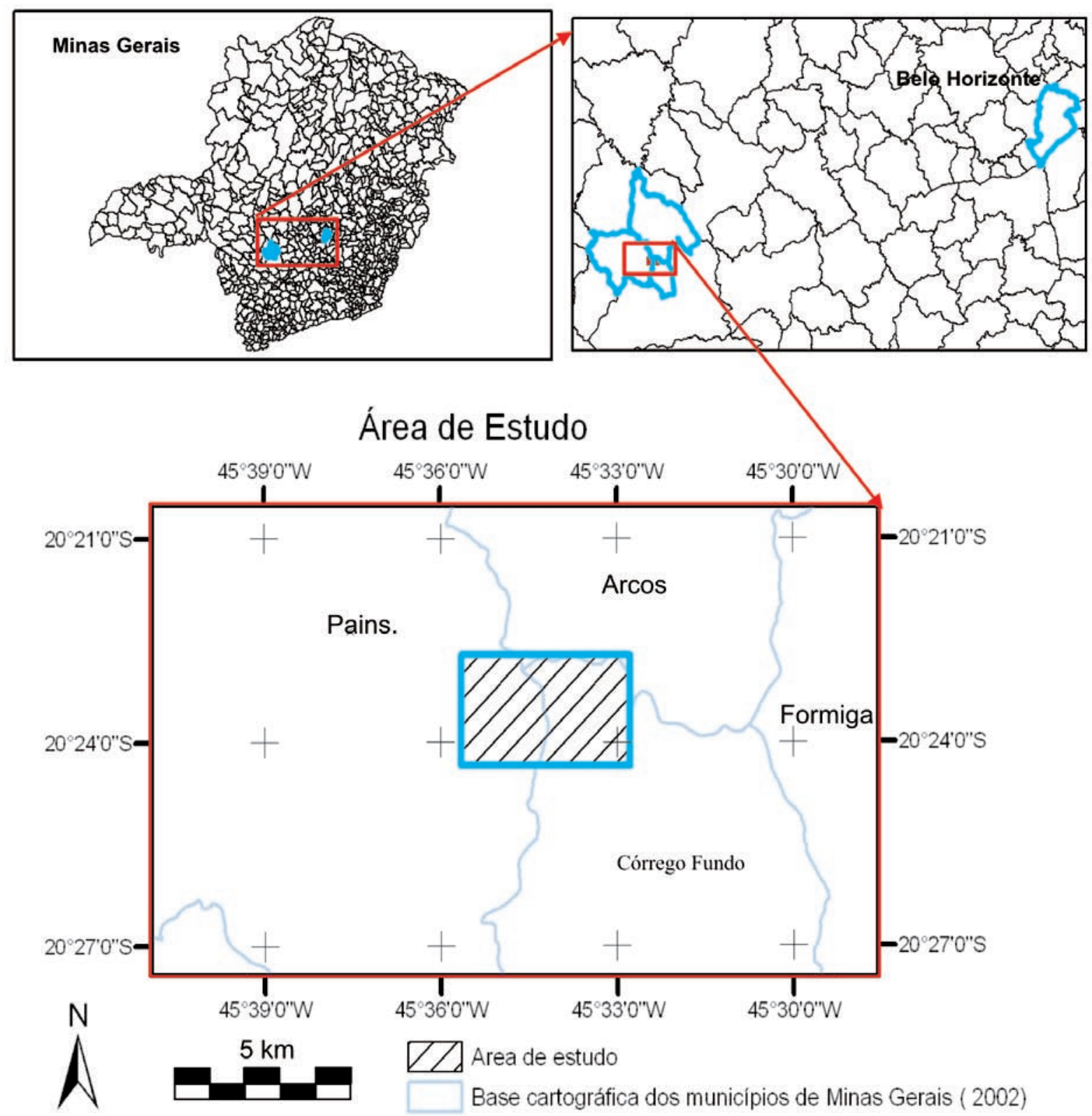

Figura 1: Área de estudo. 


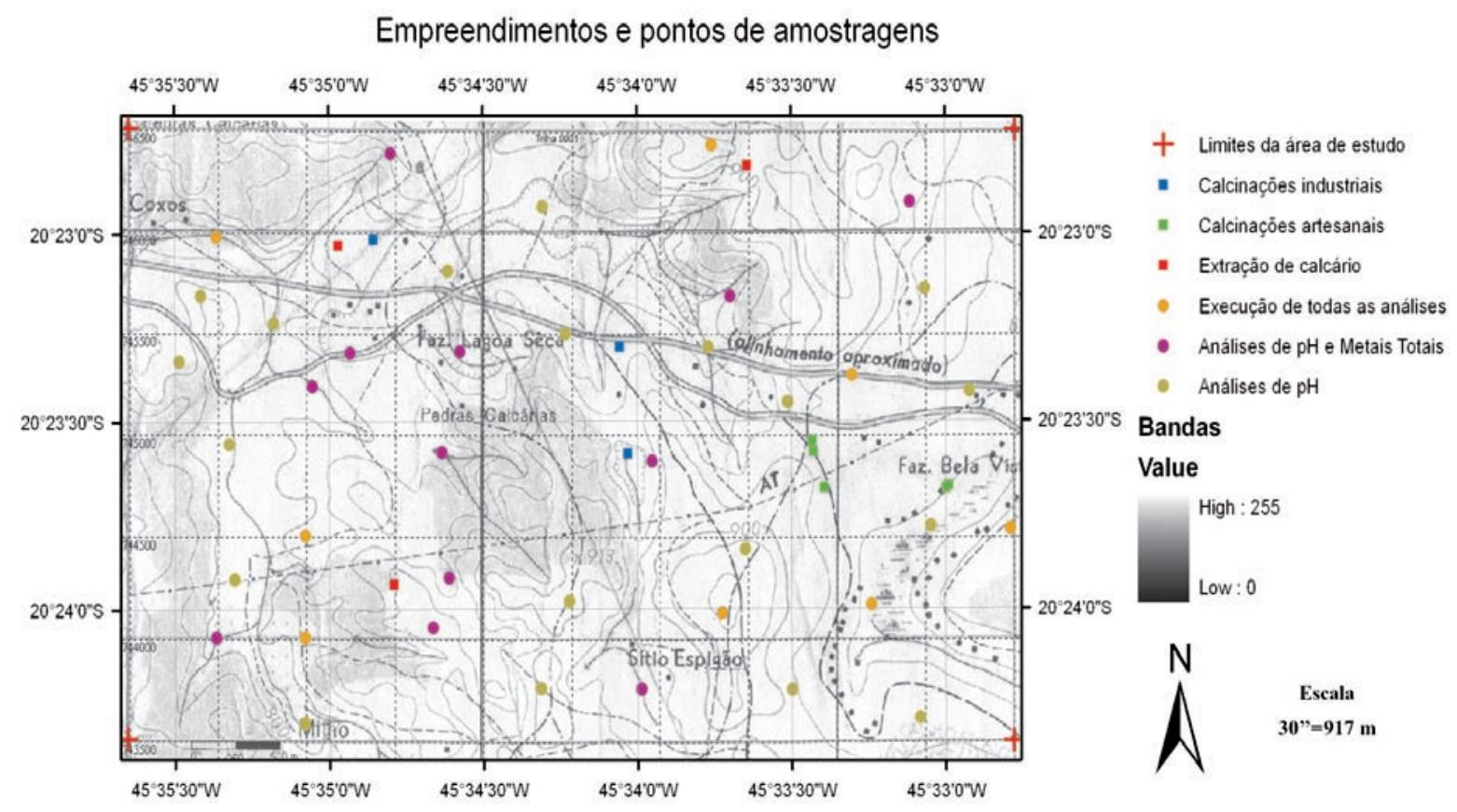

Figura 2: Empreendimentos e pontos de amostragem e na área de estudo.

(cada uma representando uma mancha geomorfológica local) foi realizada o fracionamento químico do chumbo e a quantificação dos constituintes retentores.

Definiu-se três grupos de variáveis para serem analisados. O primeiro refere-se as variáveis que efetivamente retêm o chumbo no solo por ligação química (óxidos e matéria orgânica). Um segundo grupo, representado pela capacidade de troca cationica dos solos (não um constituinte químico e sim uma ação física - atração eletrostática) de outros muitos constituintes mineralógicos e químicos (dentre eles os óxidos de ferro e alumínio) sobre o chumbo. O terceiro grupo corresponde às variáveis representativas das condições dos solos como é o caso do $\mathrm{pH}$, uma variável que influencia diretamente a capacidade de retenção dos constituintes dos solos sobre os metais pesados (Simão \& Siqueira, 2001).

A obtenção da fração argila para a quantificação dos óxidos e a determinação do $\mathrm{pH}$ ocorreram conforme EMBRAPA (1997). A quantificação dos teores totais do chumbo, bem como o fracionamento químico deste metal, ocorreram segundo Egreja Filho (1997). As demais medições (teores de óxidos, capacidade de troca catiônica e teor de matéria orgânica) foram realizadas com base em procedimentos rotineiros de laboratórios da UFV e da UFMG.

Os valores absolutos obtidos em laboratório foram relativizados por meio da sua distribuição em cinco faixas de valores. Isto ocorreu com os valores das variáveis retentoras do chumbo, com os teores totais de chumbo e com os percentuais de chumbo retidos em cada componente (obtido no fracionamento químico). Cada faixa recebeu um valor relativo que variou de 1 a 5. O valor 5 indicava a pior situação enquanto o valor 1 a melhor situação. Também foram relativizadas as forças de retenção dos constituintes dos solos. As argilas receberam valor 1 (atrações eletrostáticas menores), a matéria orgânica recebeu valor 3 (processo químico de complexação) e os óxidos receberam valor 5 (processo químico de oclusão). Porém, neste último caso, os valores 1, 3 e 5 foram pesos nas operações matemáticas para se determinar a vulnerabilidade química. A estes 5 valores foram atribuídas cores utilizadas tanto no mapa de vulnerabilidade quanto no gráfico de fracionamento químico (Tabela 1). Cores tendendo ao verde indicam a melhor situação ambiental e cores tendendo ao vermelho indicam a pior situação quanto à vulnerabilidade química $(\mathrm{Vu})$. A cor preta foi utilizada para indicar vulnerabilidade altíssima e refere-se aos afloramentos calcários e às dolinas com sumidouros.

Foi considerado que $\mathrm{Vu} \infty 1 / \mathrm{f}_{\mathrm{i}}, \mathrm{Vu} \infty \mathrm{p}_{\mathrm{i}}$ e $\mathrm{Vu} \infty$ $\mathrm{V}_{\mathrm{i}}$, ou seja, $\mathrm{Vu}=$ Somatório $\left[\left(\mathrm{p}_{\mathrm{i}} / \mathrm{f}_{\mathrm{i}}\right) \mathrm{xV}_{\mathrm{i}}\right]$. Sendo $\mathrm{f}_{\mathrm{i}}$ a força relativa com a qual cada variável i retém o chumbo (valores 1, 3 e 5); $\mathrm{p}_{\mathrm{i}}$ o percentual de metal retido na fração correspondente a variável i (valores relativos variando de 1 a 5) e $\mathrm{V}_{\mathrm{i}}$ o valor relativo a quantidade da variável retentora i. A equação de vulnerabilidade química construída e utilizada foi

$\mathrm{Vu}=\left(p_{\mathrm{CTC}} / f_{\mathrm{CTC}}\right) \mathrm{xCTC}+\left(p_{\mathrm{MO}} / f_{\mathrm{MO}}\right) \times \mathrm{MO}+\left(p_{\mathrm{O}} / f_{\mathrm{O}}\right) \mathrm{xO}$ (Equação 1)

Sendo "CTC" a capacidade de troca catiônica, "MO"o teor de matéria orgânica e "O" o teor de óxidos

Os mapas foram confeccionados na Gerência de Monitoramento e Geoprocessamento do Sistema Estadual de Meio Ambiente de Minas Gerais - SISEMA utilizando-se como base cartográfica a Folha Arcos na escala 1:50.000 (IBGE, 1970). Fez-se uso do software ArcGis, versão 9.2. Os teores do chumbo foram espacializados por meio do recurso Spline da ferramenta 
Tabela 1: Variações, magnitudes e colorações do mapa de vulnerabilidade.

\begin{tabular}{|c|c|c|}
\hline Variações de vulnerabilidade & $\begin{array}{c}\text { Magnitude da } \\
\text { Vulnerabilidade }\end{array}$ & Cores no mapa \\
\hline $\mathrm{Vu}_{\text {min real }} \mathrm{a}\left(\mathrm{Vu}_{\text {min real }}+\mathrm{F}_{\mathrm{Vu}}\right)$ & Muito baixa (1) & \\
\hline$\left(V u_{\text {min real }}+F_{V u}\right) a\left(V u_{\text {min real }}+2 F_{v u}\right)$ & Baixa (2) & \\
\hline$\left(V_{u_{\min } \text { real }}+2 F_{V u}\right) a\left(V_{\text {min real }}+3 F_{V u}\right)$ & Média (3) & \\
\hline$\left(\mathrm{Vu}_{\text {min real }}+3 \mathrm{~F}_{\mathrm{vu}}\right) \mathrm{a}\left(\mathrm{Vu}_{\text {min real }}+4 \mathrm{~F}_{\mathrm{Vu}}\right)$ & Alta (4) & \\
\hline$\left(V u_{\text {min real }}+4 F_{V u}\right)$ a $V u_{\text {max real }}$ & Muito alta (5) & \\
\hline
\end{tabular}

de análise espacial (Spatial Analist) do ArcGis de forma a se gerar um mapa de isoteores de chumbo. Quanto às manchas geomorfológicas, estas foram construídas (vetorizadas) sobre uma imagem digital da área. Previamente, realizou-se o georreferenciamento da imagem para a posterior vetorização. Para cada feição (mancha geomorfológica), foram atribuídos os valores das três variáveis retentoras do chumbo. Desta forma, foram construídos dois mapas vetorizados: um mapa para as variáveis retentoras do chumbo (Capacidade de Troca Catiônica - CTC; Teor de Matéria Orgânica e Teor de Óxidos (ferro e alumínio)) e um mapa para a vulnerabilidade química ao chumbo.

\section{RESULTADOS E DISCUSSÃO}

A área de alta concentração de chumbo (quadrante sudoeste da Figura 3) coincide com uma elevação natural (formato de colina). Segundo Borghetti (2002) e com base nas verificações de campo, ventos vindos de leste passam por locais onde encontram calcinações artesanais antes de chegarem a esta colina. Esta pode ser a razão deste pico de concentração de chumbo nas partes mais altas da colina pois os poluentes trazidos pelo vento se depositariam mais frequentemente nestes locais. Os teores de chumbo encontrados chamam a atenção uma vez que os valores de prevenção (72,0 mg/ $\mathrm{kg})$ e de intervenção nos casos de uso agrícola (216,5 $\mathrm{mg} / \mathrm{kg}$ ) são ultrapassados. Tais valores normativos são definidos pela Companhia de Tecnologia de Saneamento Ambiental (CETESB, 2005).

A Figura 4 apresenta os valores dos constituintes dos solos retentores do chumbo e a Tabela 2 relaciona tais constituintes com as respectivas manchas geomorfológicas. Já a Figura 5 apresenta os resultados do fracionamento químico do chumbo nas amostras de solos. É evidente que tal metal predomina ligado por adsorção e oclusão aos óxidos de ferro e alumínio. A CTC, relacionada à capacidade de interações eletrostáticas entre os constituintes de granulometria

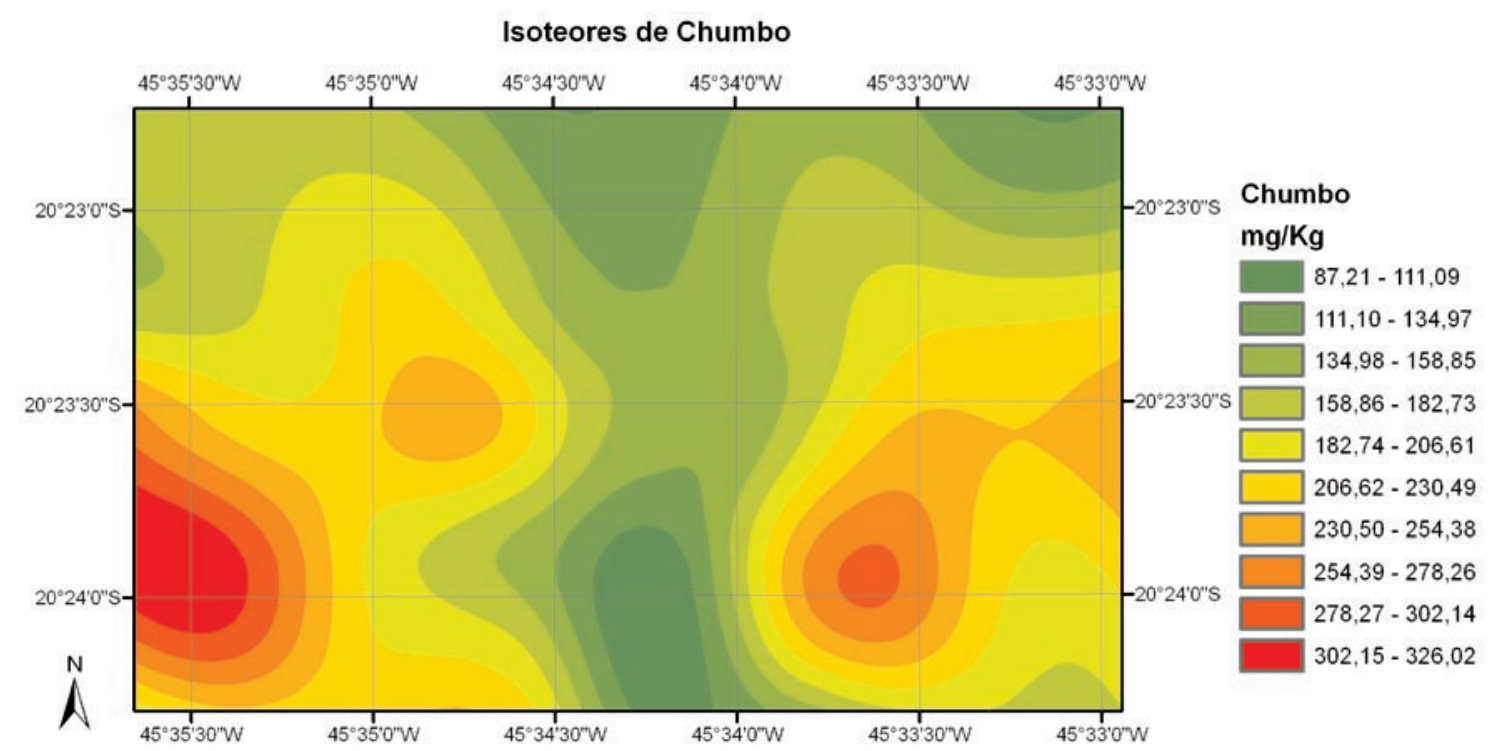

Figura 3: Isoteores de chumbo nos solos. 


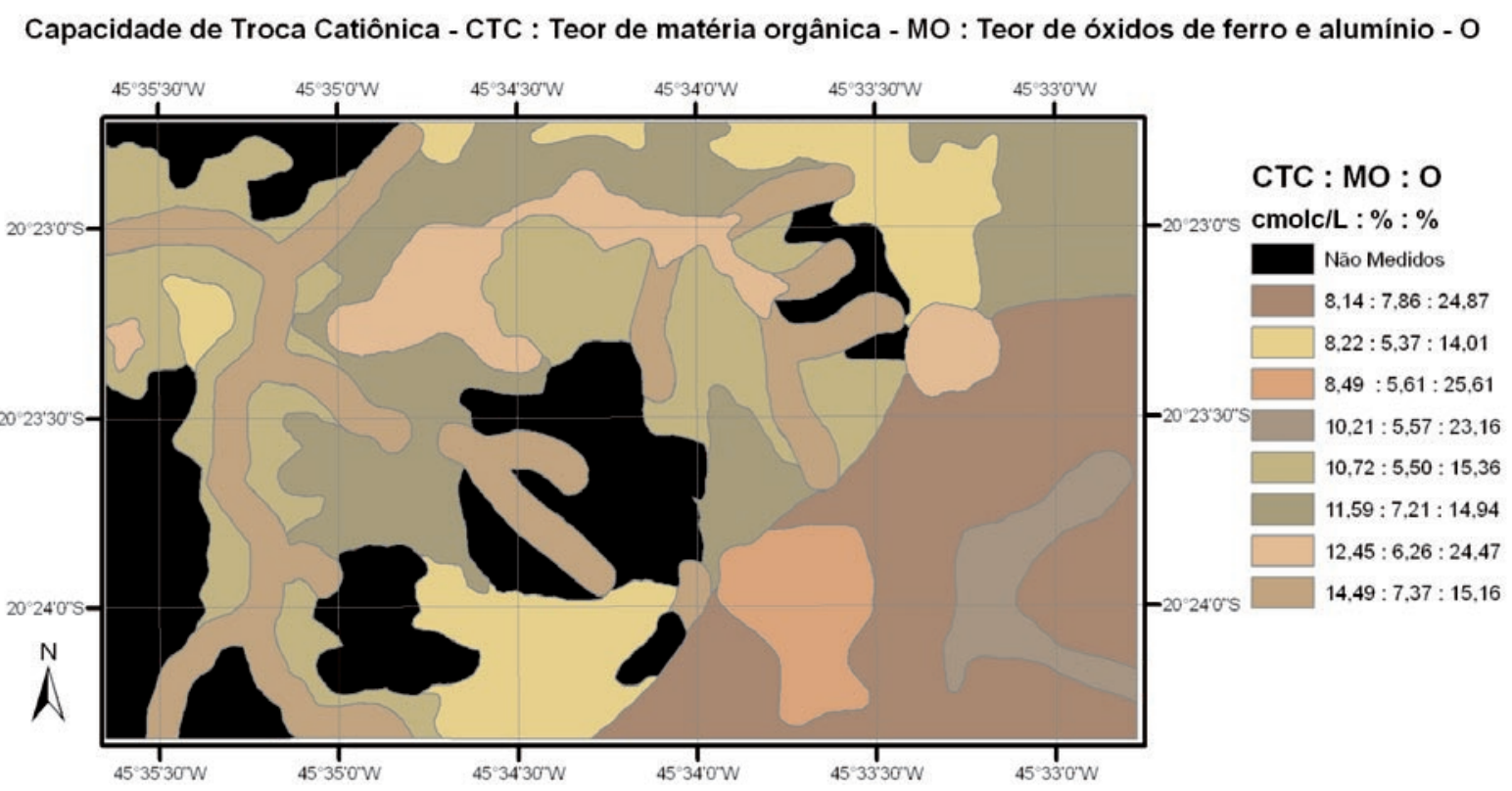

Figura 4: Teores de óxidos, matéria orgânica e capacidade de troca catiônica obtidos para as oito manchas geomorfológicas analisadas.

fina dos solos com os cátions metálicos, tende a ser maior onde a concentração de tais constituintes for maior. Nos processos de decomposição e transporte de materiais, as partículas mais finas são carreadas e depositam-se em áreas mais planas e com cotas mais baixas. Este fato é um indicativo dos maiores valores nas dolinas sem sumidouro e nas margens de drenagem. Os valores de óxidos maiores predominaram nas manchas de Latossolos e nas dolinas sem sumidouros. Tal fato é esperado para os Latossolos devido ao seu processo de formação (elevada drenagem que proporcionou um ambiente oxidante e a presença de rochas parentais com ferro e alumínio). No caso observado nas dolinas, a explicação provável é o acúmulo dos óxidos presentes na fração argila no fundo das mesmas.

Com base na Tabela 2 e Figura 4, verifica-se que a capacidade de troca catiônica nas dolinas sem sumidouro e nas margens de drenagem são as maiores. Tal variável, relacionada à capacidade de interações eletrostáticas entre os constituintes de granulometria fina dos solos com os cátions metálicos, tende a ser maior onde a concentração de tais constituintes for maior.

Tabela 2: Constituintes retentores e manchas geomorfológicas

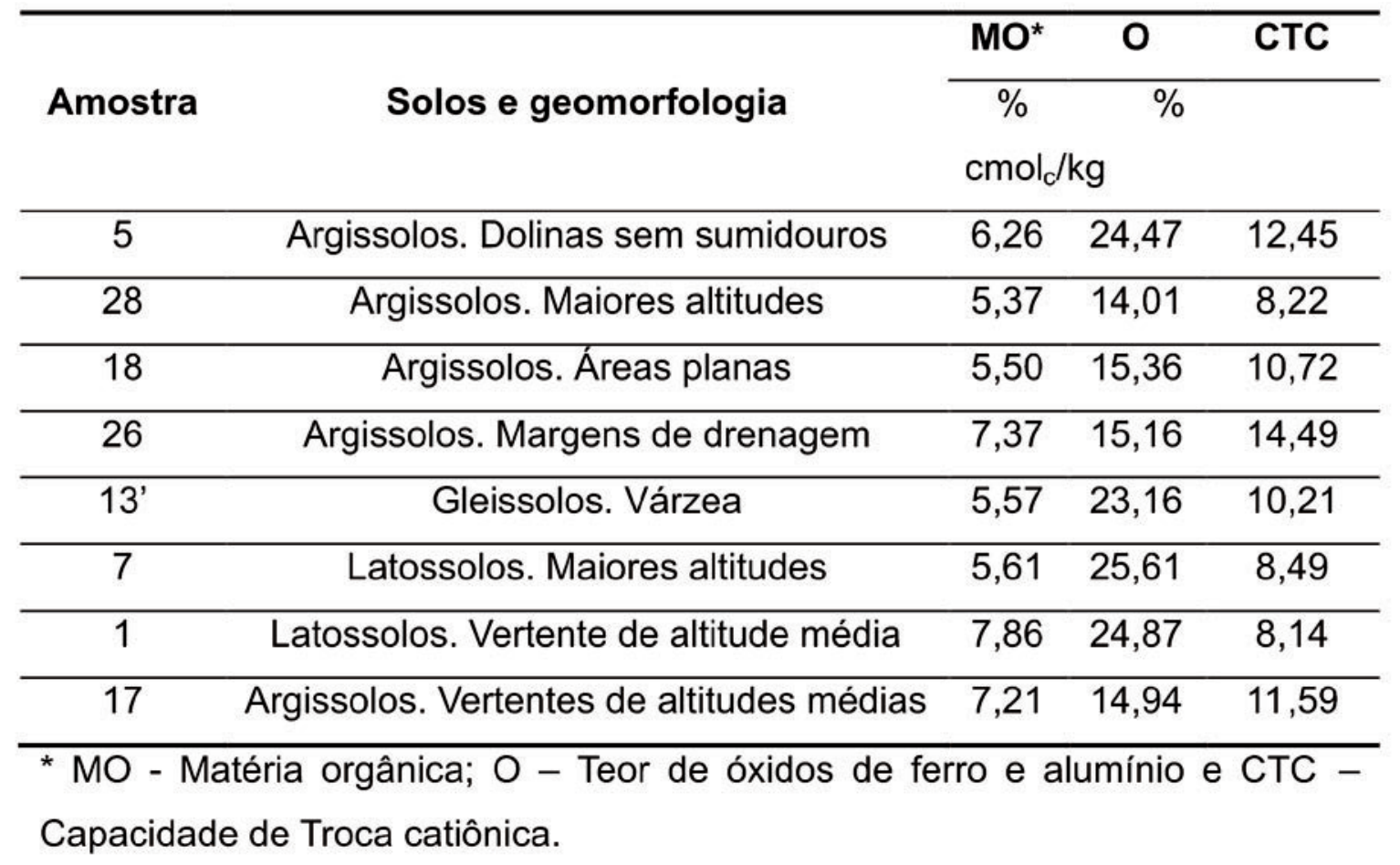


Nos processos de desfragmentação, decomposição e transporte de materiais, as partículas mais finas são carreadas e depositam-se em áreas mais planas e com cotas mais baixas. Este fato é um indicativo dos maiores valores de CTC observados nestas localidades. Em contrapartida, as manchas marrons escuras e amarelas, de locais de altitudes médias e mais elevadas, respectivamente, possuem menores valores de CTC.

Valores de óxidos de ferro e alumínio maiores predominaram nas manchas de Latossolos e nas manchas de Argissolos Eutróficos (dolinas sem sumidouros). Tal fato é esperado para os Latossolos e, semelhante ao observado nas dolinas, a explicação provável é o acúmulo dos óxidos presentes na fração argila no fundo das mesmas.

Parte-se do pressuposto que é vantajoso o chumbo ficar retido nos solos, por sua dispersão não ser contínua cuja maioria do substrato corresponde ao calcário, as vulnerabilidades muito baixas e baixas ocorreram em áreas de altitudes menores (margens de drenagem a áreas adjacentes) e em dolinas sem sumidouro. Por outro lado, as vulnerabilidades maiores ocorreram em áreas altas. É a resposta esperada do método que contemplou variáveis indicadoras dos constituintes retentores dos metais. Nos Gleissolos a vulnerabilidade química foi muito alta.

Como não se deseja a percolação dos contaminantes e a consequente contaminação das águas subterrâneas, áreas de vulnerabilidades químicas baixas e muito baixas podem ser consideradas ambientes que possuem resistência e resiliência suficientes ao aporte do chumbo. Porém, esta propriedade ocorrerá enquanto a capacidade dos constituintes dos solos em reter os metais não for ultrapassada. Enfim, a retenção é limitada. Desta forma,

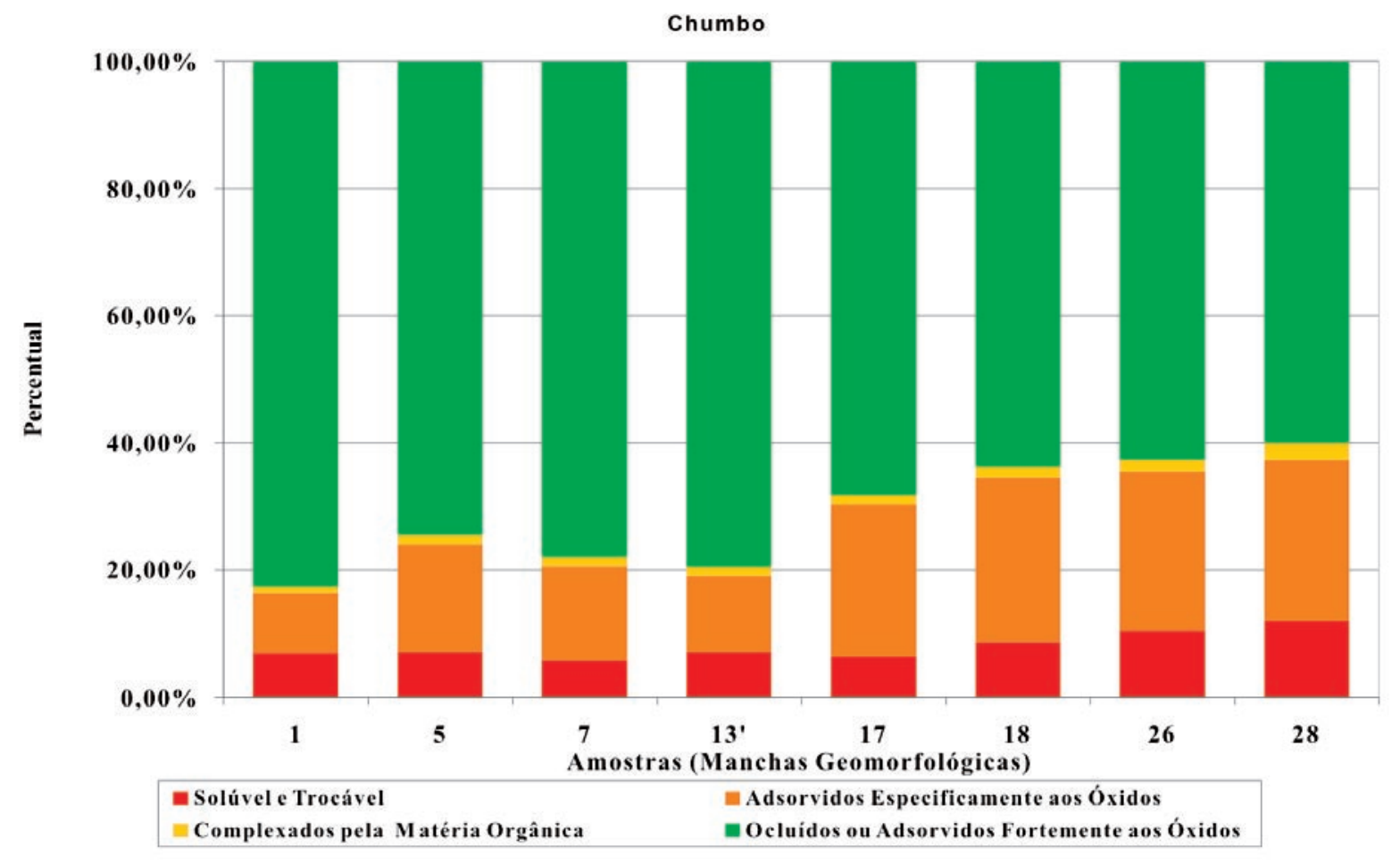

Figura 5: Fracionamento químico do metal chumbo.

espacial e temporalmente. Na verdade, ocorre a concentração e a bioacumulação deste metal em outros compartimentos ambientais. Sendo a fase solúvel e trocável aquela com maior risco de causar danos notase, pelos gráficos de fracionamento químico, que o chumbo é um elemento pouco móvel no perfil dos solos. Tal resultado está em conformidade com as conclusões de Ianhez (2003).

Nos Gleissolos (áreas de cotas baixas - várzea), Latossolos e nos Argissolos de maiores altitudes, a vulnerabilidade química para o chumbo foi muito alta. A primeira observação a se fazer refere-se ao fato de que o comportamento da vulnerabilidade, nos diferentes solos (Latossolos, Argissolos e Gleissolos), foi diferente (Figura 6). Para as manchas localizadas nos Argissolos, faz-se necessário conhecer também, antes de decidir sobre o uso dos solos de uma área, a capacidade suporte dos solos, ou seja, por quanto tempo eles suportarão determinada taxa de aporte de contaminantes e a quantidade total destes que poderá ser aplicada.

Este modelo de cálculo de vulnerabilidade química apresentado refere-se à análise da vulnerabilidade dos solos do ambiente estudado com base nos constituintes químicos. Profundidade das águas subterrâneas, condutividade hidráulica, capacidade suporte do solo e outros fatores também devem ser considerados quando se deseja avaliar uma vulnerabilidade mais ampla (vulnerabilidade global).

Áreas de cotas elevadas, mediante o critério único da profundidade das águas subterrâneas, são 


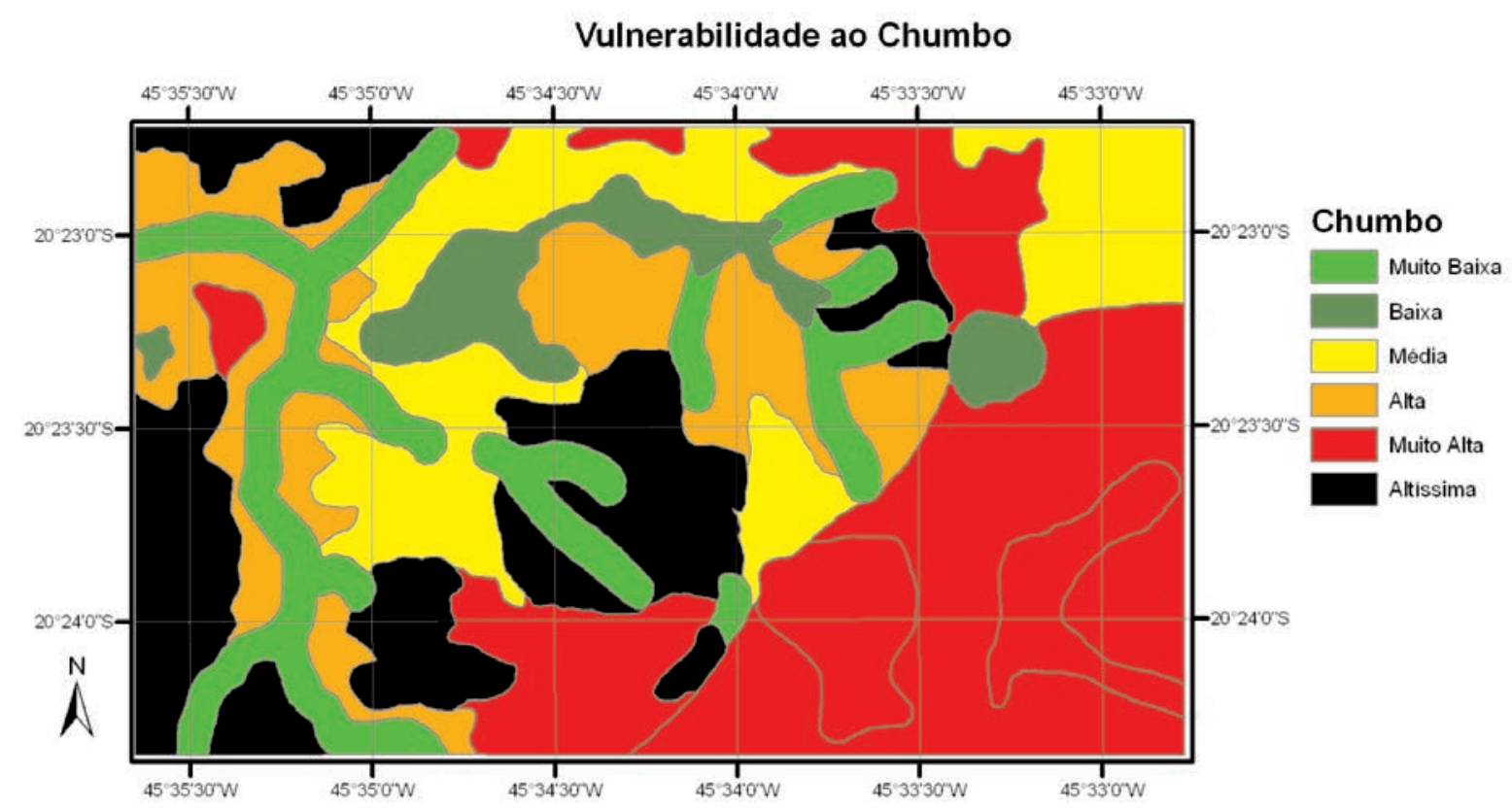

Figura 6: Mapa de vulnerabilidade química do solo ao metal chumbo.

adequadas às atividades humanas. Sob o ponto de vista das vulnerabilidades químicas aqui calculadas e da possibilidade de serem áreas de recarga hídrica, não são adequadas a estas atividades.

Neste trabalho foi abordada uma metodologia para o cálculo de uma vulnerabilidade parcial chamada de vulnerabilidade química, a qual pode ser entendida como uma espécie de vulnerabilidade parcial. Uma vulnerabilidade global contemplaria outras variáveis. É uma vulnerabilidade química por ter feito uso de variáveis químicas (CTC, matéria orgânica e teor de óxidos de ferro e alumínio). Por outro lado, uma vulnerabilidade física poderia considerar outras variáveis (profundidade de aqüíferos, declividade, condutividade hidráulica e etc). A vulnerabilidade global, um modelo que mais se aproxima da demanda real para avaliação de riscos de danos (ambientais e humanos), deveria considerar todas estas vulnerabilidades atribuindo a cada uma sua respectiva importância.

O modelo de cálculo de vulnerabilidade química mostrou-se eficaz e atendeu aos objetivos outrora propostos. Entretanto, quando se desejar calcular a vulnerabilidade global deverá ocorrer uma ampliação das áreas de restrição máxima.

Foram considerados como possuindo restrição máxima (vulnerabilidades altíssimas, cor preta no mapa) apenas as áreas de afloramentos calcários e dolinas com sumidouros. Nota-se, porém, que outras restrições, relacionadas às variáveis de cálculo da vulnerabilidade física e biológica, devem ser consideradas. É o caso de se restringir, por exemplo, as áreas de cursos d'água, sejam intermitentes ou perenes, assim como uma faixa (buffer) no entorno destas (especificamente as áreas de preservação permanentes - APP); as áreas de preservação da fauna e/ou flora; áreas de valor social e patrimonial e outras, de acordo com as suas especificidades. As dolinas sem sumidouro também devem sofrer restrições, não pela vulnerabilidade química, mas com base em outros aspectos restritivos.

As restrições das manchas quanto ao uso por atividades lançadoras de chumbo no meio ambiente são proporcionais ao grau de vulnerabilidade. Quanto maior a vulnerabilidade maior deve ser a restrição.

\section{CONCLUSÕES}

O cálculo da vulnerabilidade química do chumbo contemplou a retenção deste metal pelos constituintes químicos dos solos, a força com que esta retenção ocorre bem como a contribuição percentual de retenção de cada constituinte. Assim, as variáveis químicas primordiais e específicas foram contenpladas. A vulnerabilidade global pode ser obtida por meio do uso de todas as variáveis em um modelo global ou pela união da vulnerabilidade química com as demais vulnerabilidades (vulnerabilidades ecológica, física e humana).

Os teores de chumbo encontrados na área demandam atenção porque boa parte deles supera os limites de intervenção estabelecidos pela CETESB. O mapa de isoteor e a presença de certos empreendimentos na área de estudo sugerem que sua origem pode ser de tais empreendimentos. O gráfico de fracionamento químico mostra que as interações entre o chumbo e os solos predominam nos óxidos de ferro e alumínio por adsorção e oclusão química.

\section{AGRADECIMENTOS}

À Fundação Estadual do Meio Ambiente - Feam e ao Instituto de Geociências - IGC/UFMG pelo apoio na construção deste trabalho. 


\section{REFERENCIAS BIBLIOGRÁFICAS}

BORGHETTI C. 2002. A Influência da Indústria Calcinadora na Distribuição e na Concentração de Metais Pesados na Região de Córrego Fundo - Pains (MG). Dissertação de Mestrado, Instituto de Geociências, Universidade Federal de Minas Gerais, 71 p.

CETESB - Companhia de Tecnologia de Saneamento Ambiental 2005. (São Paulo). Decisão de diretoria No 195-2005-E, de 23 de novembro de 2005, 4 p.

EGREJA FILHO F. B. 1997. Extração seqüencial de metais pesados em solos altamente intemperizados: utilização de componentesmodelo e planejamentos com misturas ternárias na otimização do método. Tese de Doutorado, Universidade Federal de Viçosa, $287 \mathrm{p}$.

EMBRAPA - EMPRESA BRASILEIRA DE PESQUISA AGROPECUÁRIA. Centro Nacional de Pesquisas de Solos. 1997. Manual de Métodos de Análise de Solo. 2 ed. rev. atual. Rio de Janeiro, 212 pp.

IANHEZ R. 2003. Fracionamento Químico de Metais Pesados em Solos Contaminados por Resíduos Industriais e Otimização Quimiométrica de Misturas para a Descontaminação por Lixiviação Química. Dissertação de Mestrado, Universidade Federal de Minas Gerais, 158 p.

IBGE - Instituto Brasileiro de Geografia e Estatística 1970. Folha Arcos. SF-23-C-I4. Rio de Janeiro, Mapa Topográfico, escala $1: 50.000$.
KARMANN I. 2001. Ciclo da Água, água subterrânea e sua ação geológica. In: W. Teixeira, M. C. M. Toledo, T. R. Fairchild \& F. Taioli (org.). Decifrando a terra. Reimpressão. Oficina de Textos, São Paulo, p.: 113-138.

LEMOS R. C. de \& Santos R. D. dos. 1996. Manual de descrição e coleta de solo no campo. Sociedade Brasileira de Ciência do Solo. $3^{\mathrm{a}}$ ed. Campinas, $84 \mathrm{pp}$.

MATOSINHOS C. C. 2004. Avaliação de risco ecológico como estratégia para a prevenção da poluição industrial: estudo de caso para o setor têxtil. Dissertação de Mestrado, Universidade Federal de Minas, $180 \mathrm{p}$.

MENEGASSE L. N., GONÇALVES, J. M., FANTINEL, L. 2002. Disponibilidades Hídricas na Província Cárstica de Arcos - Pains - Doresópolis, Alto São Francisco, Minas Gerais, Brasil. Rev. Águas Subterrâneas, 16: 1-19.

PAIM L. A. 2002. Contaminação do solo por metais pesados: silício e fósforo como agentes amenizadores. Dissertação de Mestrado, Universidade Federal de Lavras, 67 p.

SANTOS C. I. F. 2002. As Relações entre Endocarste e Exocarste na Província Cárstica de Arcos - Pains - Doresópolis/MG. Dissertacao de Mestrado, Instituto de Geociências, Universidade Federal de Minas Gerais, 69 p.

SIMÃO, J. B. P. \& SIQUEIRA, J. O. 2001. Solos Contaminados por Metais Pesados: Caracteristicas, implicacoes e Remedicao. In: Informe Agropecuário. Belo Horizonte, 210: 18 - 265. 